INRA Prod. Anim., 2007, 20 (4), 295-308

\section{Authentification de l'alimentation des ruminants à partir de la composition de leurs produits et tissus}

\author{
S. PRACHE , B. MARTIN 1 , P. NOZIERE 1 , E. ENGEL ${ }^{2}$, J.-M. BESLE 1 , A. FERLAYl,

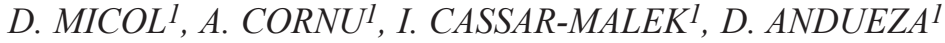 \\ 1 INRA, UR1213 Herbivores, F-63122 Saint-Genès Champanelle, France \\ 2 INRA, UR370 Qualité des Produits Animaux, F-63122 Saint-Genès Champanelle, France
}

Courriel :prache@clermont.inra.fr

\begin{abstract}
Savoir comment les animaux d'élevage ont été nourris est une demande forte des consommateurs et un enjeu majeur pour les filières. La nature de l'alimentation influence fortement la composition des tissus et produits animaux. Cette dernière traduit donc le mode d'élevage de l'animal et peut ainsi permettre de l'authentifier. Des méthodes ont été récemment développées pour tracer l'alimentation des ruminants sur les produits laitiers et carnés.
\end{abstract}

Les consommateurs sont demandeurs d'informations et de garanties sur les conditions d'élevage des animaux et en particulier leur alimentation. Ces préoccupations conduisent les filières à prendre des engagements sur les conditions d'élevage et d'alimentation des animaux, engagements qui sont spécifiés dans des cahiers des charges. Les recherches conduites sur le thème de l'authentification de l'alimentation des ruminants visent à développer des outils analytiques permettant, à partir de la composition des produits et des tissus animaux, de remonter aux conditions d'élevage des animaux, et ainsi de garantir le respect des engagements des cahiers des charges, voire d'aider à les instruire.

L'analyse de ces engagements (voir par exemple le travail de Roche et al (2000) pour les Label Rouge gros bovins de boucherie) permet d'en dégager les modalités d'alimentation à authentifier et de définir les programmes expérimentaux correspondants. Le point a donc été fait sur ces engagements pour les produits laitiers et carnés. La réglementation nationale interdit l'utilisation de tous les produits animaux (graisses, huiles de poisson, toutes farines animales). Un engagement très fréquent concerne l'utilisation des fourrages conservés par voie humide et fermentés, souvent limitée (en agriculture biologique - AB - et pour certains Label Rouge - LR -), voire interdite pour certains LR et produits d'Appellation d'Origine Contrôlée (AOC). L'utilisation du maïs peut être limitée voire interdite sous toutes ses formes, mais dans certains cas, son utilisation peut au contraire être recommandée (un LR viande bovine privilégie le maïs grain en phase de finition). L'affouragement en vert de maïs, sorgho et crucifères fourragères peut également être limité ou interdit. Les modalités d'alternance pâture/stabulation sont parfois spécifiées (par exemple, durée minimale de la période de pâturage et durée maximale de la phase de stabulation), de même que les rations de finition (par exemple, herbe obligatoire ou interdiction de l'ensilage pendant les derniers mois). Les engagements concernant les aliments concentrés (y compris les coproduits) sont nombreux et divers. Leur distribution est dans certains cas plafonnée, et leur nature est de plus en plus fréquemment spécifiée dans une liste d'aliments autorisés (dite «positive»), tous les aliments non cités étant interdits. Le soja et ses coproduits posent un problème particulier $\mathrm{du}$ fait des suspicions d'Organisme Génétiquement Modifié (OGM) ; il n'est pas à proprement parler interdit, mais on cherche parfois à le remplacer, en particulier en AB. L'allaitement maternel du jeune peut être obligatoire jusqu'à un certain âge.
La démarche de s'appuyer sur les engagements des cahiers des charges pour en tirer des questions de recherche permet de structurer et finaliser le programme de recherches sur cette thématique. Il ne s'agit cependant pas d'en être prisonniers, puisque ces cahiers des charges peuvent être évolutifs et qu'il ne faut pas s'interdire d'être prospectif, les recherches menées pouvant d'ailleurs aider les acteurs en charge de l'élaboration ou de l'évolution des cahiers des charges à intégrer de nouveaux éléments. Par ailleurs, nous sommes conscients que certains engagements seront difficiles à objectiver par des moyens analytiques. Enfin, il faut rappeler que beaucoup de produits font déjà l'objet de contrôles ; il s'agit alors le plus souvent d'une traçabilité dite «papier» ou de contrôles par visites. Cependant, on sait que certains engagements sont impossibles à contrôler par une «traçabilité papier», et qu'en cas de litige sérieux, la production de preuves objectives à l'aide d'analyses pourrait se révéler indispensable.

Etre capable d'authentifier l'alimentation des ruminants à partir d'analyses sur leurs produits et tissus est ainsi devenu un enjeu important pour les scientifiques, les filières et les organismes de contrôle. Cette synthèse présente les avancées méthodologiques réalisées récemment, les principaux 
résultats obtenus, ainsi que les perspectives envisagées dans ce domaine. Elle traite essentiellement de l'authentification de l'alimentation, mais donne quelques aperçus de l'authentification de la provenance géographique, élément important pour les produits bénéficiant d'une indication de provenance.

\section{1 / Principe des méthodes analytiques et champ d'uti- lisation}

La nature de l'alimentation influence fortement la composition des tissus et produits de ruminants (Aurousseau et al 2004, Nozière et al 2006b, Chilliard et al 2007). Cette composition peut donc être utilisée en retour pour tracer l'alimentation. Les méthodes analytiques développées pour tracer 1'alimentation de l'animal sont de deux types. D'une part, la quantification dans les produits, tissus, fluides ou fèces des animaux de traceurs moléculaires ou atomiques dont la présence ou les proportions sont caractéristiques de l'alimentation. D'autre part, des méthodes globales telles que les méthodes spectrales et récemment la génomique fonctionnelle.

\section{1 / Traceurs moléculaires et atomiques}

\section{a) Les caroténoïdes}

Ils forment le principal groupe de pigments naturels; la lutéine est le seul stocké dans le tissu adipeux des ovins, les bovins accumulant également (et surtout) le ß-carotène (Yang et al 1992, Prache et al 2003b). Leur concentration dans les tissus et produits animaux est très liée à la quantité de caroténoïdes ingérée par l'animal (Calderón et al 2007, Dian et al 2007b). L'herbe verte est très riche en ces pigments (430 à $700 \mathrm{mg} / \mathrm{kg} \mathrm{MS}$ ). La teneur du fourrage diminue avec le séchage et la durée de conservation en liaison avec le degré d'exposition à la lumière, car ces pigments sont photodégradables. Les teneurs observées dans l'ensilage préfané sont d'environ $60 \%$ (à $28 \%$ de MS) à 30\% (à $35 \%$ de MS) de celles observées initialement dans l'herbe verte; elles sont d'environ $30 \%$ pour l'enrubannage et $20 \%$ pour le foin (Nozière et al 2006b). L'ensilage de maïs est pauvre en ces pigments (70$80 \mathrm{mg} / \mathrm{kg} \mathrm{MS}$ ), et la zéaxanthine, le caroténoïde présent dans les grains de maïs n'est pas stocké par les tissus des ruminants. La plupart des aliments concentrés sont très pauvres en caroténoïdes. C'est pourquoi ces pigments ont été proposés pour discriminer, à partir des produits et tissus d'herbivores, une alimentation à l'herbe d'une alimentation à base de concentré et de foin ou à base d'ensilage de maïs (Prache et Thériez 1999, Prache et al 2002).

\section{b) Les polyphénols}

Certaines plantes fourragères sont très riches en flavonoïdes et autres composés phénoliques intracellulaires. Plusieurs structures polyphénoliques sont souvent spécifiques de la famille botanique (voire de la variété) et des conditions environnementales, d'où leur intérêt pour tracer l'alimentation. Dans une prairie permanente de montagne du Cantal, par exemple, on a séparé plus de 170 composés différents (dont seulement 10 identifiés) et les teneurs totales ont dépassé $30 \mathrm{~g} / \mathrm{kg}$ MS (Fraisse et al 2007). La composition et la teneur en polyphénols varient avec l'espèce végétale et le stade de maturité de la plante, les dicotylédones en contenant beaucoup plus que les graminées. Après analyse du fourrage par chromatographie liquide haute pression (CLHP), on obtient une «empreinte chromatographique», reflet de la diversité botanique de ce fourrage au moment où il a été prélevé. Après ingestion, les polyphénols sont biotransformés dans le rumen, absorbés, remaniés dans le foie, et se retrouvent partiellement dans les tissus où ils sont métabolisés, une autre fraction étant sécrétée dans le lait ou excrétée dans l'urine. Selon la voie métabolique suivie, les molécules isolées dans divers compartiments peuvent être proches ou très différentes de celles absorbées. Dans le lait, ces composés ont permis, à partir de leur profil moléculaire, de caractériser la ration (Besle et al 2005) ou l'ingestion d'une plante particulière. Ainsi, pour une ration riche en trèfle violet, contenant des isoflavones essentiellement de la formononétine -, on retrouve dans le lait, au-delà de molécules rencontrées avec d'autres régimes, de l'équol qui provient de la dégradation de la formononétine et des aglycones non transformés (Sakakibara et al 2004, Besle et al 2005). Les travaux sur ces composés sont cependant très récents et leur intérêt potentiel en terme d'authentification reste encore à préciser. Une étude de la variabilité des empreintes chromatographiques des prairies, entre régions, intra-régions et selon le type de prairies, est en cours sur le territoire français. L'incidence de la composition en polyphénols du régime sur celle du lait dépendra de l'intensité de la fermentation, définissant le profil des produits absorbés, et de l'interaction entre la nature du régime et les caractéristiques animales, dont la variabilité individuelle. Dans la mesure où l'on peut trouver dans le lait des composés phénoliques à la fois d'origine endogène et provenant de la ration, on pourra distinguer des composés (ou des fractions de profil chromatographique) communs à l'ensemble des régimes étudiés, et d'autres, plus spécifiques à un régime et à une zone géographique donnés. Des études sont en cours sur l'identification et le transfert de ces molécules des plantes dans le lait.

\section{c) Les acides gras}

La nature de certains Acides Gras (AG) sécrétés dans le lait ou stockés dans les tissus adipeux dépend fortement de l'alimentation. La composition en $\mathrm{AG}$ du lait ou de la viande peut ainsi être utilisée en retour pour tracer l'alimentation de l'animal. Les AG du lait ont une double origine : $40 \%$ ( $\mathrm{AG}$ à chaîne courte et moyenne, $\leq 16$ atomes de carbone) proviennent de la synthèse de novo mammaire principalement à partir d'acétate et de $\beta$-hydroxybutyrate provenant de la fermentation ruminale des glucides, et $60 \%$ ( $\geq 18$ atomes de carbone) sont prélevés dans le plasma (Chilliard et al 2007). Les AG à 18 atomes de carbone et plus sont issus directement de l'alimentation ou proviennent de la mobilisation des tissus adipeux. Les AG impairs et/ou ramifiés représentent une faible part des $\mathrm{AG} d u$ lait et sont synthétisés par la microflore bactérienne du rumen. Les AG polyinsaturés (AGPI, principalement acides linoléique et linolénique) d'origine alimentaire subissent une biohydrogénation ruminale liée à l'activité microbienne, produisant des intermédiaires de la biohydrogénation ruminale (isomères cis et trans des C18:1, C18:2 et C18:3) et l'acide stéarique. Les AGPI n'étant pas synthétisés par les tissus des ruminants, leur concentration dans le lait dépend des quantités absorbées dans l'intestin, et donc des quantités quittant le rumen. Les différentes composantes de la ration (nature et mode de conservation du fourrage, rapport fourrage/concentré, teneur en amidon de la ration) et la supplémentation lipidique (nature, modalités d'apport, dose et durée de la supplémentation) sont les principaux facteurs alimentaires capables de modifier le métabolisme ruminal des AGPI et par conséquent d'in- 
fluencer le profil des AG quittant le rumen (Chilliard et al 2007). Ces mêmes facteurs modifient en partie la synthèse bactérienne dans le rumen des AG mineurs à chaîne impaire et (ou) ramifiée (Vlaeminck et al 2006). L'ensilage de maïs, les céréales ou les concentrés et les graines oléagineuses telles que le soja et le tournesol sont riches en acide linoléique, tandis que l'herbe verte et les graines de lin sont les principales sources d'acide linolénique. Le fanage réduit les concentrations des AG totaux et de l'acide linolénique dans l'herbe, les modifications dues à l'ensilage étant intermédiaires (Chilliard et al 2007). La combinaison des différents facteurs alimentaires induit des variations assez importantes dans la composition du lait en AG. Ainsi, l'herbe pâturée à un stade précoce conduit à des laits plus riches en C18:1cis9 et en acide ruménique (principal isomère des CLA dans le lait) et plus pauvres en acide linoléique que des rations riches en concentré ou à base d'ensilage de maïs (Ferlay et al 2006). Les AGPI et les intermédiaires de leur biohydrogénation ruminale, de même que les AG mineurs d'origine bactérienne, sont ainsi susceptibles d'apporter des informations intéressantes pour tracer l'alimentation des animaux.

\section{d) Les composés volatils}

La nature et la quantité des constituants volatils présents dans les produits et tissus des ruminants sont fortement influencées par l'alimentation (Vasta et Priolo 2006). Il s'agit de traceurs moléculaires qui peuvent être soit des constituants volatils de la ration, soit des produits volatils du métabolisme exprimés de manière différentielle en fonction du régime (Berdagué et al 2005). Ces composés sont extraits par la technique d'espace de tête dynamique puis analysés par le couplage de la chromatographie en phase gazeuse $(\mathrm{CPG})$ et de la spectrométrie de masse (SM), avec des développements méthodologiques récents (Deport et al 2006).

Parmi les substances volatiles désorbant des produits laitiers ou carnés, les terpènes ont fait l'objet de nombreuses études. Les terpènes volatils sont les monoterpènes et les sesquiterpènes, molécules composées de 10 et 15 atomes de carbone, et leurs dérivés oxygénés. Ils ont une origine presque exclusivement végétale. Le déterminant principal de la teneur des fourrages est la composition botanique : les fourrages à base de graminées en sont très pauvres, alors que ceux à base de prairies diversifiées, avec un nombre élevé d'espèces dicotylédones aromatiques, en sont beaucoup plus riches (Mariaca et al 1997, Cornu et al 2001a, Bugaud et al 2001). La teneur des plantes en terpènes varie également avec le stade de maturité ; elle est généralement plus élevée à un stade tardif qu'à un stade précoce (Cornu et al 2001a, Tornambé et al 2006). L'identification des terpènes dans les produits laitiers est ancienne : Dumont et Adda (1978) et Dumont et al (1981) avaient montré que les fromages de Comté ou de Beaufort produits en montagne étaient nettement plus riches en terpènes que leurs homologues produits en plaine. Par la suite, des comparaisons des fractions terpéniques de différents fourrages et des laits et des fromages correspondants ont montré que les terpènes des fourrages étaient transférés rapidement et sans grande modification dans les produits laitiers (Viallon et al 1999 et 2000, Bugaud et al 2001). Les foins caractérisés par une grande diversité d'espèces végétales et en particulier de dicotylédones présentaient des teneurs supérieures et une plus grande diversité en terpènes, diversité qui se retrouvait dans les fromages correspondants. Il a ainsi été proposé que la diversité en terpènes pourrait constituer l'empreinte d'un terroir : Bosset et al (1994) par exemple, ont proposé d'utiliser ces composés pour reconnaître les fromages Suisses de l'Etivaz produits en alpage, et Carpino et al (2004) ont identifié certains terpènes spécifiques aux fromages issus de laits de vaches pâturant des prairies permanentes siciliennes.

L'analyse directe des effluves désorbées par les produits, sans étape chromatographique, peut également fournir une information très riche, assimilable à une signature, ou empreinte, des produits. Cette technique se justifie lorsque l'on désire seulement caractériser ou typer un produit à partir de son empreinte, sans information complémentaire sur sa composition. Après constitution d'une banque de données représentative d'une situation donnée, la signature de l'échantillon inconnu est comparée à celles des échantillons constitutifs de la banque. La similitude entre deux signatures (ou certains éléments des signatures) est à la base des opérations de reconnaissance/classification qui utilisent des techniques de modélisation statistique ou neuronale (Engel et Ratel 2006).

\section{e) La composition isotopique}

Les proportions d'isotopes stables de certains éléments chimiques, tels que ceux de l'oxygène (oxygène de masse 18 par rapport à celui de masse 16 ${ }^{18} \mathrm{O} /{ }^{16} \mathrm{O}$ ou $\left.\delta^{18} \mathrm{O}-\right)$, de l'hydrogène $\left({ }^{2} \mathrm{H} /{ }^{1} \mathrm{H}\right.$ ou $\left.\delta^{2} \mathrm{H}\right)$, du carbone $\left({ }^{13} \mathrm{C} /{ }^{12} \mathrm{C}\right.$ ou $\left.\delta^{13} \mathrm{C}\right)$ et de l'azote $\left({ }^{15} \mathrm{~N} /{ }^{14} \mathrm{~N}\right.$ ou $\left.\delta^{15} \mathrm{~N}\right)$ sont sujettes à variation naturelle. Les causes de ces variations sont bien connues et certaines d'entre elles présentent un intérêt en terme d'authentification de l'origine géographique et/ou des conditions d'élevage et d'alimentation des ruminants.

Ces variations peuvent en effet être liées aux conditions climatiques et environnementales, à l'altitude et à la latitude, comme c'est le cas pour $\delta^{18} \mathrm{O}$ et $\delta^{2} \mathrm{H}$ dans l'eau, ce qui permet d'utiliser l'analyse de $\delta^{18} \mathrm{O}$ et $\delta^{2} \mathrm{H}$ dans l'eau des produits laitiers et de la viande pour obtenir des informations sur l'origine géographique des produits correspondants (Rossmann et al 2000, Renou et al 2004a, b). Néanmoins, la variabilité saisonnière de la composition isotopique de l'eau des produits doit être prise en compte pour pouvoir utiliser cette méthode à des fins d'authentification de l'origine géographique (Kornexl et al 1997). En effet, l'eau consommée par les animaux provient préférentiellement de l'eau de boisson dans le cas d'un régime à base de fourrages secs, alors que dans le cas du pâturage, l'eau contenue dans les plantes est plus riche en ${ }^{18} \mathrm{O}$ du fait de l'évaporation préférentielle de ${ }^{16} \mathrm{O}$, elle-même variable selon le climat.

Les variations naturelles des proportions d'isotopes stables peuvent aussi être liées à la physiologie de l'organisme végétal ou animal. Ainsi, les plantes terrestres en $\mathrm{C}_{4}$ présentent une proportion en ${ }^{13} \mathrm{C}$ plus élevée que les plantes en $\mathrm{C}_{3}$, du fait de voies métaboliques différentes lors de la photosynthèse (Gebbing et al 2004). La plage de variation de $\delta^{13} \mathrm{C}$ est ainsi de - $14 \%$ à - $10 \%$ pour les plantes en $\mathrm{C}_{4}$ contre - $35 \%$ à - $21 \%$ pour les plantes en $\mathrm{C}_{3}$ (Kelly 2000, cité par Schmidt et al 2005). Les tissus et produits d'animaux alimentés avec du maïs (plante en $\mathrm{C}_{4}$ ) sont ainsi plus riches en ${ }^{13} \mathrm{C}$ que ceux d'animaux pâturant de l'herbe de prairies tempérées (plantes en $\mathrm{C}_{3}$ ) (Piasentier et al 2003, Gebbing et al 2004). Cependant, cette analyse ne permet pas de révéler un engraissement intensif avec d'autres céréales que le maïs, et un engraissement avec une ration à base de maïs peut également être confondu avec un engraissement 
sur graminées prairiales tropicales en $\mathrm{C}_{4}$ (Gebbing et al 2004, Schmidt et al 2005). Quant au rapport $\delta^{15} \mathrm{~N}$ dans les plantes, il est modulé par la fertilisation minérale qui augmente la teneur en ${ }^{15} \mathrm{~N}$ de leurs composés azotés. La proportion en légumineuses dans les prairies a l'effet inverse, en lien avec la fixation de l'azote atmosphérique (Gebbing et al 2004, Schmidt et al 2005). Le rapport $\delta^{15} \mathrm{~N}$ dans les tissus et produits animaux pourrait ainsi indiquer le degré d'intensification des prairies et des cultures destinées à l'alimentation des animaux, et présenter un intérêt pour distinguer les produits animaux issus de systèmes à faibles intrants (Schmidt et al 2005).

L'alimentation de l'animal et le lieu où il vit peuvent ainsi déterminer la composition isotopique de ses tissus et produits. En retour, l'analyse de celle-ci, réalisée par spectrométrie de masse des rapports isotopiques (SMRI), peut donner des informations pertinentes sur l'alimentation de l'animal et son origine. Cependant, le fait que les animaux consomment souvent des mélanges d'aliments, qu'ils peuvent subir des alternances de régimes, et qu'ils peuvent avoir été déplacés au cours de leur vie, complexifie l'application de cette méthode.

\section{2 / Méthodes globales}

a) Méthodes basées sur les propriétés optiques

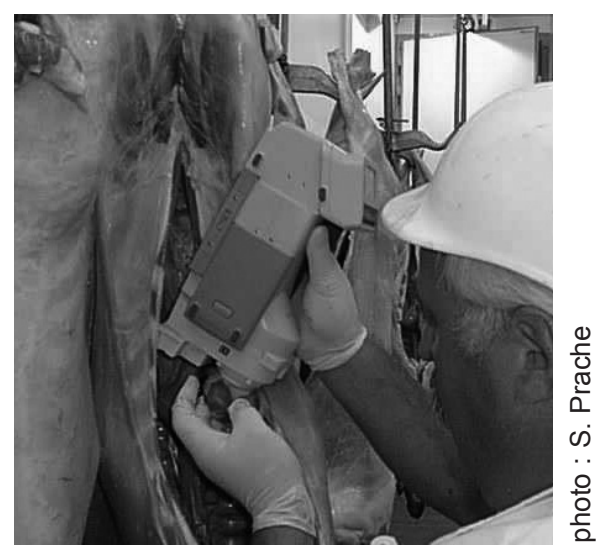

Mesure de la signature optique du mode d'alimentation sur le gras de rognon d'une carcasse d'agneau par spectrométrie dans le visible à l'aide d'un spectrocolorimètre portable.

Les différences dans la composition des produits, tissus, fluides et fèces liées à des différences dans l'alimentation de l'animal provoquent des modifications de leurs propriétés optiques qui peuvent être utilisées en retour pour authentifier l'alimentation. La spectrométrie dans le visible (VIS) a ainsi été utilisée sur le lait (Nozière et al 2006c) et la viande ovine (Dian et al 2007a) à des fins d'authentification de l'alimentation des animaux. Le spectre de réflectance du produit dans la zone du visible $(400-700 \mathrm{~nm})$ est mesuré à l'aide d'un spectrocolorimètre portable (MINOLTA CM-2002), puis analysé par analyse discriminante utilisant l'approche PLS-DA pour discriminer les régimes alimentaires expérimentés et identifier les zones spectrales d'intérêt dans la discrimination. Cette méthode a permis de confirmer la contribution majeure de la zone d'absorption de la lumière par les pigments caroténoïdes dans la discrimination entre agneaux d'herbe et agneaux de bergerie à partir du spectre de réflectance du tissu adipeux dans le visible (Dian et al 2007a). Un index spectrocolorimétrique (IS), calculé à partir du spectre de réflectance dans le visible, permet de quantifier la «signature» de ces pigments et d'estimer leur concentration (Prache et Thériez 1999, figure 1). Un brevet a été déposé sur ce procédé (Prache et Priolo 2003), qui présente l'avantage d'être simple, portable, rapide et peu coûteux, et qui a été étendu à la viande bovine et aux produits laitiers (Prache et al 2002, Nozière et al 2006a et c, Serrano et al 2006b). Bien qu'un peu moins facile d'utilisation car non portable, la spectrométrie dans le visible et le procheinfrarouge (VIS-IR) pourrait permettre d'améliorer la qualité de la discrimination en élargissant la gamme explorée du spectre de réflectance (400$2500 \mathrm{~nm})$. Ces méthodes spectrales,

Figure 1. Spectre de réflectance du tissu adipeux périrénal pour (a) un agneau ayant un index spectrocolorimétrique (IS) élevé (agneau élevé à l'herbe), et (b) un agneau ayant un IS faible (agneau de bergerie alimenté avec du concentré et du foin).

Proportion de lumière réfléchie (déviation par rapport à la proportion de lumière réfléchie à $510 \mathrm{~nm})(\%)$

(a)

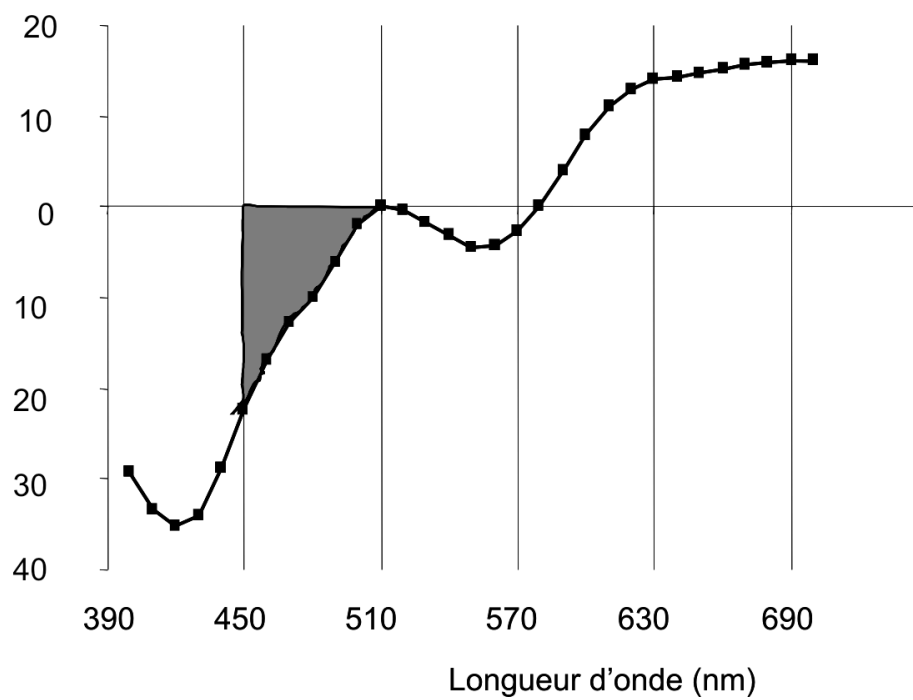

(b)

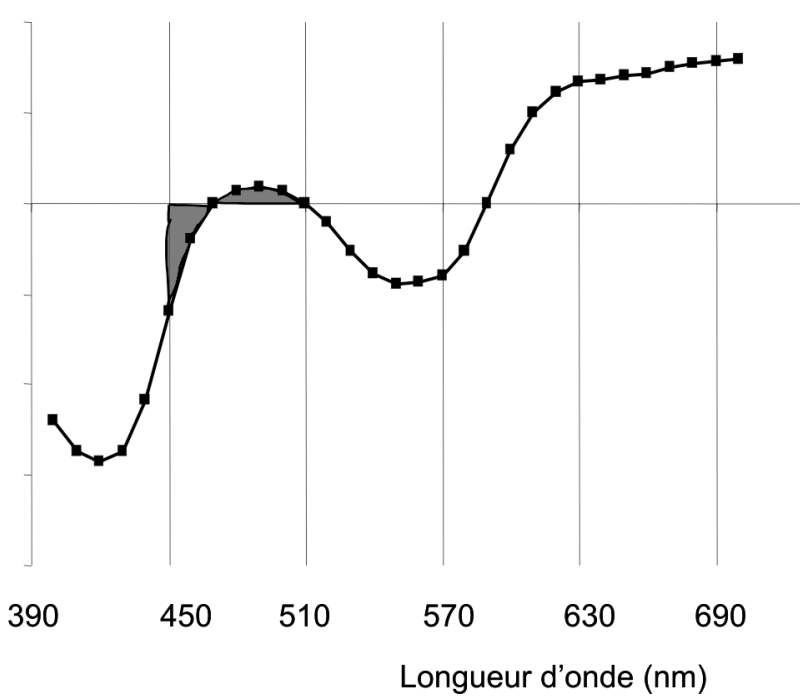

L'index spectrocolorimétrique est la valeur absolue de la surface grisée comprise entre la courbe et l'axe X dans la zone 450 à 510 nm, zone d'absorption de la lumière par les pigments caroténoïdes. Cet index est une estimation indirecte de la teneur du tissu adipeux en pigments caroténoïdes (Prache et al 2003b). 
assez simples à mettre en œuvre, ont probablement un potentiel d'application très important.

\section{b) Génomique fonctionnelle}

La régulation de l'expression des gènes est sous le contrôle de différents facteurs dont les nutriments. En retour, le profil d'expression des gènes pourrait donc donner des informations pertinentes sur les conditions d'alimentation de l'animal. Des techniques d'analyse de génomique fonctionnelle ont été récemment développées afin de comparer les profils d'expression des gènes (transcriptomique) ou de protéines (protéomique) dans les échantillons tissulaires d'animaux d'intérêt agronomique (Hocquette et al 2005). Des méthodes d'analyse globale des transcrits à l'aide de réseaux à $\mathrm{ADN}$, ou des protéines par électrophorèse bidimensionnelle, sont utilisées afin d'identifier des ensembles de gènes et de protéines définissant une "signature moléculaire» des tissus, qui pourrait être associée à certaines conditions d'alimentation des animaux.

\section{2 / Discrimination de régi- mes alimentaires contrastés}

La première étape, pour évaluer le potentiel des différents traceurs pressentis, consiste à comparer des régimes alimentaires très contrastés, voire extrêmes, l'objectif n'étant pas seulement de mettre en évidence des différences significatives entre régimes, mais bien de les discriminer avec le maximum de fiabilité.

\section{1 / Produits laitiers}

En conditions expérimentales, la discrimination de laits issus de régimes à base d'herbe pâturée, comparativement à des régimes à base de foin et de concentrés est relativement aisée grâce aux méthodes spectrales basées sur les propriétés optiques du lait. Dans une expérimentation comparant du lait et des fromages (Cantal et Saint Nectaire) issus d'animaux au pâturage ou recevant une alimentation à base de concentrés $(55 \%)$ et de foin $(45 \%)$, la mesure de l'index spectrocolorimétrique a permis de discriminer sans erreur les deux régimes, aussi bien pour le lait que pour les deux types de fromages (figure 2, Prache et al 2002). Une simple mesure de l'indice de jaune avait par ailleurs permis de différencier sans erreur des fromages issus d'animaux recevant de l'ensilage d'herbe de ceux

Figure 2. Distribution de la valeur de l'index spectrocolorimétrique quantifiant la concentration en pigments caroténoïdes dans différents produits d'herbivores, pour des animaux alimentés à l'herbe pâturée (blanc) ou avec du concentré et du foin (noir).

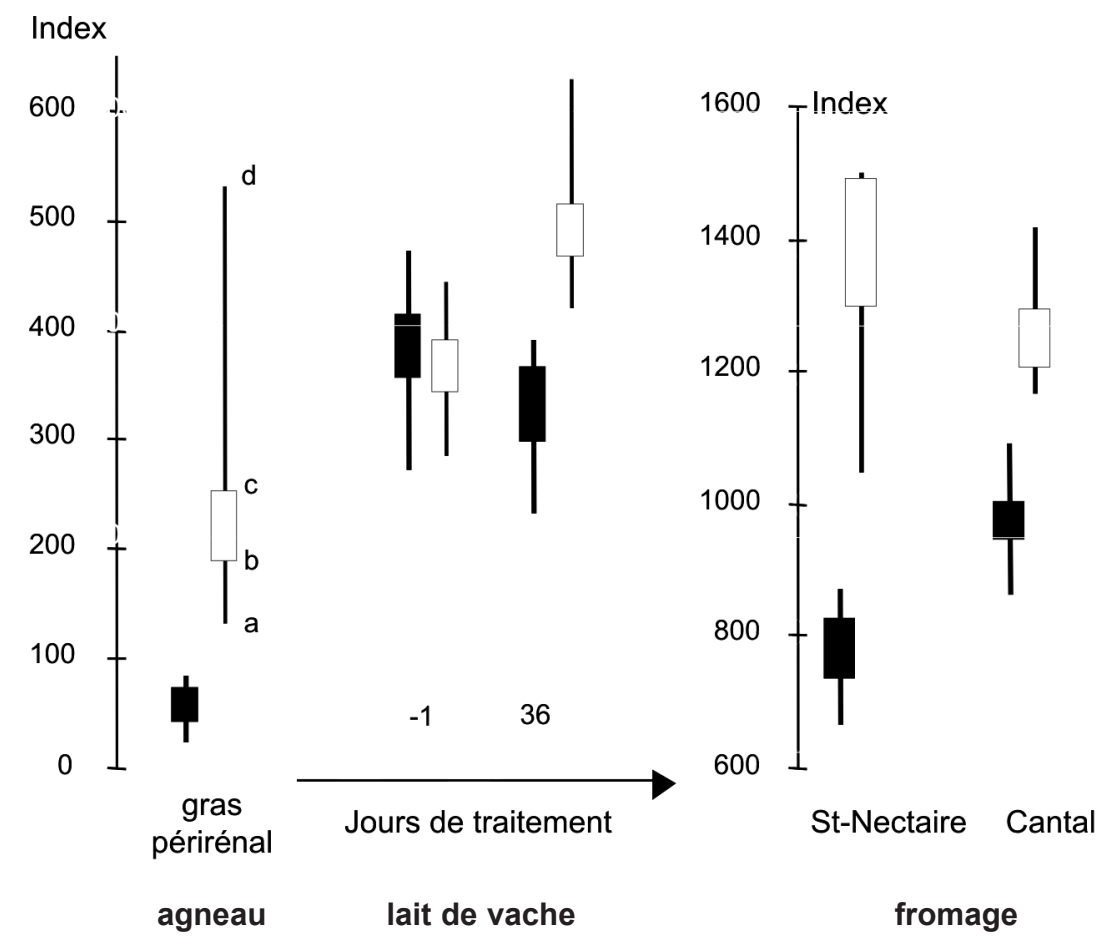

Les lettres a et $d$ indiquent les valeurs minimales et maximales, $50 \%$ des valeurs sont comprises entre b et c (Prache et al 2002).

issus d'animaux recevant $\mathrm{du}$ foin (Verdier-Metz et al non publié). Ces mesures ont également permis de discriminer le lait d'animaux recevant des régimes à base de concentrés ou de foin de prairie naturelle de celui produit par des animaux recevant des régimes à base d'herbe ensilée ou pâturée (Martin et al 2005). Enfin, la comparaison des spectres de réflectance par approche PLS-DA a permis de discriminer des laits produits soit avec du foin soit avec de l'ensilage d'herbe avec une réussite de $90 \%$ pour VIS (400-700 nm) et $87 \%$ pour VIS-IR (400-2500 nm) (Nozière et al 2006c).

Au-delà de ces premiers travaux où deux situations extrêmes étaient comparées, une expérimentation a été mise en place pour couvrir une plus large gamme de situations alimentaires. Six régimes ont été comparés : ration riche en concentrés (orge et tourteau de soja représentant $65 \%$ de la MS ingérée), à base d'ensilage de maïs, d'ensilage de ray-grass, de foin de ray-grass, de foin de prairie naturelle, ou à base d'herbe de prairie naturelle pâturée.

Dix terpènes, le $\beta$-carotène et 5 acides gras - en particulier les acides linolénique, ruménique et vaccénique - ont permis d'apporter au cas par cas des informations pertinentes pour discrimi- ner l'un des régimes par rapport à tous les autres. Les terpènes considérés seuls ont permis de classer correctement $93 \%$ des laits, malgré de fortes similitudes entre profils (Martin et al 2005). Les laits obtenus sur le pâturage à flore diversifiée étaient facilement identifiables : ils contenaient, selon les terpènes, entre 6 et 23 fois plus de ces composés que les laits obtenus avec les autres fourrages, y compris le foin de prairie naturelle à flore diversifiée. Les laits «ensilage de ray-grass» et «foin de ray-grass» d'une part et «ensilage de maïs» et «concentré» d'autre part formaient deux sous-groupes difficiles à distinguer à partir du dosage des seuls terpènes. Par ailleurs, les laits obtenus avec le même foin de prairie naturelle, mais stocké plus ou moins longtemps (8 ou 11 mois) présentaient des profils similaires mais les quantités de terpènes étaient plus faibles dans le cas du foin conservé plus longtemps. La volatilisation progressive des terpènes au cours du stockage du fourrage pourrait donc amener à confondre des fourrages initialement riches mais conservés longtemps avec des fourrages initialement plus pauvres mais conservés moins longtemps. Le seul dosage de la fraction terpénique des laits n'a donc pas été suffisant pour discriminer sans erreur tous les régimes. La teneur en $\beta$-carotène a permis de distinguer les 
laits «ensilage de maïs» des laits «ensilage d'herbe» ou «herbe pâturée». La teneur en acide linolénique (C18:3) a permis de discriminer les laits obtenus avec de l'ensilage de maïs ou du concentré de ceux produits au pâturage. L'acide ruménique (9cis, 11 trans $\mathrm{C} 18: 2$, principal isomère des acides linoléiques conjugués - CLA -) a permis, quant à lui, de distinguer le régime «concentré» des autres. Au final, dans cet essai, c'est seulement la mise en œuvre simultanée de plusieurs de ces techniques qui a permis de discriminer sans ambiguïté la totalité des régimes testés. En particulier, 8 terpènes et 5 acides gras utilisés dans des modèles non linéaires de type réseaux de neurones multicouches ont permis de classer avec succès $100 \%$ des laits analysés (Martin et al 2005).

Dans cette expérimentation, plus d'une centaine de composés phénoliques ont été séparés dans le lait par CLHP. Les deux tiers d'entre eux étaient présents dans les laits de tous les régimes et représentaient plus de $90 \%$ de la surface des pics. Parmi les autres, certains se sont révélés spécifiques d'un régime donné. Ainsi, les différences de teneurs en composés communs et la présence de composés spécifiques permettent de définir un profil chromatographique typique d'une ration qui pourrait ainsi être utilisé pour authentifier l'alimentation. C'est le régime à base d'herbe de prairie naturelle pâturée qui a présenté la concentration la plus élevée ainsi que la plus grande diversité en composés phénoliques (Besle et al 2005).

En outre, les laits provenant de pâturages des Alpes ont un profil en composés phénoliques nettement différent de ceux provenant de pâturages d'Auvergne (Besle et al non publié). De même, les fromages de 5 régions différentes ont pu être différenciés en utilisant ces composés (Besle et al non publié). L'identification des composés phénoliques par SM et résonance magnétique nucléaire (RMN) est en cours de réalisation. De même, l'utilisation des terpènes pour reconnaître la provenance géographique et/ou la nature du régime a été testée sur des laits de troupeaux prélevés soit en Bretagne (pâturage de prairies temporaires en été et ration à base d'ensilage de maïs en hiver), soit en Auvergne (pâturage de prairies permanentes en été et rations à base de foin ou d'ensilage d'herbe de prairies permanentes en hiver). Le seul dosage des terpènes du lait a permis de discriminer sans erreur les 4 groupes de laits (Figure 3, Fernandez et al 2003).

Figure 3. Discrimination des laits selon la zone de production ("Auvergne = •", "Bretagne $=\boldsymbol{\Delta}$ ") et l'alimentation saisonnière. L'analyse factorielle discriminante a été réalisée avec 6 sesquiterpènes : $\delta$-élemène, $\beta$-bourbonène, $\beta$-caryophyllène, $\beta$-chamigrène, $\gamma$-cadinène et $\beta$-sesquiphellandrène (Fernandez et al 2003).

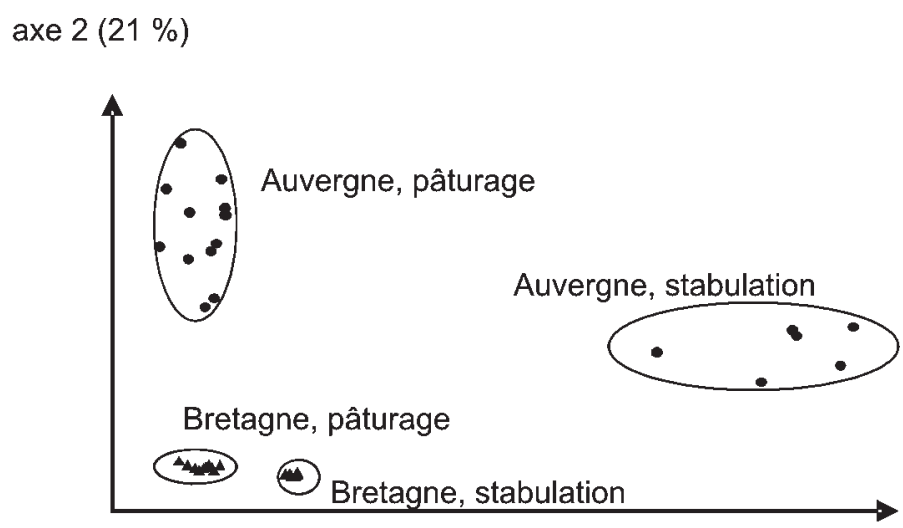

axe $1(68 \%)$

\section{2 / Produits carnés}

\section{a) Viande ovine}

Un ensemble d'expérimentations ont été conduites pour tester les traceurs potentiels de l'alimentation chez l'agneau (voir synthèse plus détaillée de Prache et al 2005). Deux régimes ont été comparés : pâturage exclusif d'herbe verte feuillue $(\mathrm{H})$ vs distribution de concentré et de foin en bergerie (85\% et $15 \%$ de la ration respectivement, B). Le niveau alimentaire des agneaux $\mathrm{B}$ était ajusté de manière à obtenir un profil de croissance similaire à celui des agneaux $\mathrm{H}$. Le niveau de caroténoïdes ingérés par les agneaux B n'a atteint que 2-3\% de celui ingéré par les agneaux $\mathrm{H}$ (Prache et al 2003a). La concentration en caroténoides dans le sang et le tissu adipeux (Priolo et al 2002, Prache et al 2003a et b), en certains composés volatils dans le tissu adipeux (terpènes et 2,3-octanedione, Priolo et al 2004), et la composition en acides gras de la viande (Aurousseau et al 2004) ont chacun permis de discriminer sans erreur les agneaux $\mathrm{H}$ des agneaux B. Les agneaux H présentaient 5 à 6 fois plus de caroténoïdes dans le plasma, 2,4 à 4,1 fois plus de lutéine et 25 fois plus de 2,3-octanedione dans le gras que les agneaux B. Les sesquiterpènes, et en particulier le $\beta$-caryophyllene, le trans-cadina-1(6),4-diene, l' $\alpha$ et le $\beta$-cubebene étaient présents à des niveaux significatifs chez les agneaux $\mathrm{H}$ et seulement à des niveaux basaux voire non détectables chez les agneaux B. Concernant la composition en acides gras des lipides de la viande, le rapport C18:2n-6/C18:3n-3 dans les phospholipides du muscle longissimus thoracis variait de 10 à 25 pour les agneaux $B$ contre 2 à 5 pour les agneaux $\mathrm{H}$, per- mettant ainsi de les discriminer sans erreur. Dans cette expérimentation, l'index spectrocolorimétrique calculé à partir du spectre de réflectance du tissu adipeux dans la zone d'absorption de la lumière par les pigments caroténoïdes a permis de discriminer sans erreur agneaux $\mathrm{H}$ et $\mathrm{B}$ (figure 2). Cette mesure doit être faite préférentiellement sur le gras périrénal plutôt que sur le gras sous cutané, à cause de différences de concentration entre sites de dépôts (Priolo et al 2002, Dian et al 2007b).

Les rapports d'isotopes stables du carbone et de l'azote ont également été utilisés chez l'agneau pour authentifier le régime alimentaire. Chez des agneaux nourris pendant la phase de finition avec soit du lait, soit de l'herbe pâturée, soit un concentré contenant du maïs grain, la combinaison des valeurs $\delta^{13} \mathrm{C}$ du gras, $\delta^{13} \mathrm{C}$ et $\delta^{15} \mathrm{~N}$ des protéines a permis de discriminer correctement $91,7 \%$ des échantillons de muscle longissimus thoracis (Piasentier et al 2003).

\section{b) Viande bovine}

Dans un souci de valorisation des ressources naturelles et de l'image des produits, certains cahiers des charges s'engagent sur la limitation de l'apport d'aliment concentré dans la ration. Un travail visant à apporter des éléments objectifs permettant de contrôler le respect d'un tel engagement sur l'animal vivant est en cours de développement. Cette approche est basée sur l'analyse des constituants alimentaires non digestibles excrétés dans les fèces. Un premier essai réalisé sur des génisses ingérant 2,4 ou $6 \mathrm{~kg} / \mathrm{j}$ de concentré a montré que le respect du cahier des charges $(\leq 4 \mathrm{~kg} / \mathrm{j})$ pouvait être garanti 
avec un taux de réussite de $98 \%$ en déterminant le spectre dans le proche infra-rouge (par spectrométrie VIS-IR) d'un échantillon de fèces prélevé sur l'animal (Nozière et al 2005). Cette méthode est maintenant testée dans des conditions d'alimentation moins «expérimentales» et plus proches de celles de la pratique (distribution à volonté de foin de qualité variable).

Une étude récente avec des veaux Salers élevés et engraissés sous la mère et abattus à 9-11 mois (Serrano et al $2006 \mathrm{a}$ et $\mathrm{b}$ ) a permis de faire converger et de montrer les complémentarités entre les différentes approches analytiques présentées plus haut. Les animaux ont reçu deux types de fourrages (herbe de prairie naturelle offerte à l'auge $v s$. foin de graminées) et deux niveaux de complémentation en concentré (haut vs. bas); un dernier lot pâturait une estive à flore très diversifiée avec une complémentation à volonté. Les caroténoïdes et la 2,3octanedione se sont révélés bien adaptés au marquage de la nature des fourrages (vert vs. fourrage sec), les terpènes au repérage de l'utilisation de pâtures à flore diversifiée (estive), et la spectrométrie VIS-IR - via les fèces à la quantification du ratio fourrages/concentrés. La mesure de la teneur plasmatique en caroténoïdes et du spectre de réflectance des tissus adipeux à l'abattage a permis de discriminer les animaux qui recevaient de l'herbe de ceux qui recevaient du foin, le tissu périrénal étant plus discriminant, comme pour la viande ovine. Pour les composés volatils, la 2,3-octanedione était présente dans les tissus adipeux des animaux conduits à l'herbe, mais pas dans les autres régimes. Les profils terpéniques les plus riches des tissus gras, tant en diversité qu'en intensité, ont été obtenus chez les veaux pâturant les estives. Dès leur plus jeune age, les bovins incorporent donc dans leurs tissus les marqueurs de l'alimentation, via le lait maternel puis l'alimentation solide. L'analyse des fèces par la spectrométrie VIS-IR a permis de discriminer les deux niveaux de complémentation avec une erreur de seulement $2 \%$.

Dans une autre expérimentation, la spectrométrie VIS-IR utilisée sur le muscle longissimus dorsi a permis de discriminer des bœufs alimentés soit à l'herbe soit avec une ration à base d'ensilage de maïs, avec une réussite de $81 \%$ (Cozzolino et al 2002).

Par ailleurs, chez des bœufs de 30 mois conduits à l'auge (ensilage de

Figure 4. Sous-expression, dans le muscle Rectus Abdominis, du gène de la Sélénoprotéine $W$ dans le régime Herbe Pâturée par rapport au régime Ensilage de Maïs (Cassar-Malek et al 2005).
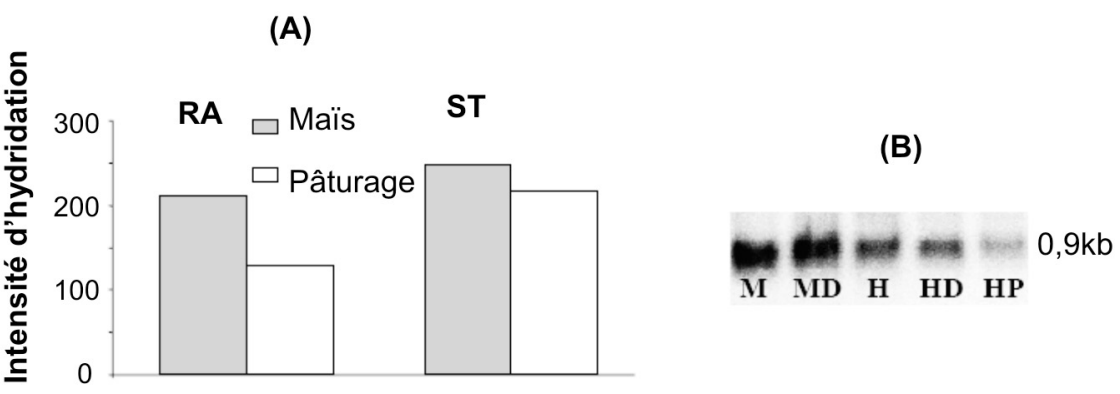

(A) Résultats d'hybridation sur les membranes des ARNm des boeufs au pâturage vs boeufs alimentés à l'auge avec de l'ensilage de maïs, dans les muscles Rectus Abdominis (RA) et Semitendinosus (ST)

(B) Détection de l'ARNm sélénoprotéine W par Northern-Blot à l'aide d'une sonde bovine ADNc. Lots : $\mathrm{M}$, ensilage de maïs (auge) ; $\mathrm{MD}$, ensilage de maïs avec $1 \mathrm{~h}$ de déplacement quotidien ; $\mathrm{H}$, herbe coupée (auge) ; HD, herbe coupée avec 1 h de déplacement quotidien ; HP, herbe pâturée.

maïs) ou au pâturage, Cassar-Malek et al (2005) ont cherché à identifier des gènes dont l'expression est associée à la conduite au pâturage. Le transcriptome musculaire a été analysé afin d'étudier les transcrits des gènes musculaires et de révéler l'expression de gènes associée à la conduite au pâturage. Les profils transcriptionnels des gènes ont été comparés à l'aide de réseaux d'ADNc de ruminants (Collection AGENAE Muscle, Embryon et Mamelle). Deux cent vingt cinq transcrits musculaires exprimés différentiellement selon la conduite ont été identifiés. Ce sont majoritairement les produits de gènes codant pour des enzymes du métabolisme musculaire, des protéines contractiles et des protéines ribosomiques. Le résultat original est la détection d'une sous-expression $\mathrm{du}$ gène de la sélénoprotéine $\mathrm{W}$ associée à la conduite au pâturage, des analyses complémentaires suggérant qu'elle serait davantage liée à la teneur ou à la biodisponibilité du sélénium (inférieure dans l'herbe par rapport à l'ensilage de maïs) plutôt qu'à l'exercice musculaire des animaux à la pâture (figure 4). L'expression de ce gène pourrait ainsi constituer un marqueur de la conduite au pâturage.

Enfin, les profils chromatographiques des terpènes du muscle, utilisés comme empreintes, se sont avérés des marqueurs intéressants de la localisation géographique des pâturages. Ces empreintes ont en effet permis de reconnaître sans erreur quatre groupes de 6 bœufs élevés l'un à l'ensilage de maïs et les autres au pâturage dans trois régions de France : Auvergne, Normandie, Lorraine (Cornu et al 2001b). Ces résultats prometteurs ont toutefois été obtenus avec des animaux expéri- mentaux ayant suivi un parcours simple depuis leur naissance jusqu'à l'abattage vers l'âge de 24 mois.

\section{3 / Capacité à discriminer des régimes alimentaires moins contrastés}

La comparaison de régimes alimentaires simples et contrastés, discutée jusqu'à présent, est indispensable pour mettre en évidence les traceurs potentiels. Cependant, la réalité peut être plus complexe, les régimes moins contrastés, et les engagements des cahiers des charges concernent très souvent les modalités d'alternance de régimes ou les rations de finition. Ceci nécessite d'étudier i) les facteurs de variation de la teneur des tissus et produits en composés d'intérêt et la capacité des méthodes identifiées précédemment à discriminer des régimes alimentaires en conditions moins contrastées, ii) les sources de biais, puisque ces outils doivent in fine être utilisés comme outils d'aide au contrôle et iii) les phénomènes de latence d'apparition et de persistance des traceurs potentiels lors d'un changement d'alimentation.

\section{1 / Etude de certains facteurs de variation et de sources de biais}

Le stade phénologique des plantes peut affecter leur teneur en traceurs d'intérêt. De plus, dans le cas de l'alimentation à l'herbe, la conduite des animaux au pâturage peut moduler leurs choix alimentaires et les quantités d'herbe qu'ils ingèrent et donc l'ingestion des traceurs correspondants. Les 
facteurs de variation spécifiquement animaux, tels que la race et le niveau de production, peuvent également moduler la réponse animale mais n'ont pas encore été étudiés expérimentalement.

a) Effet du stade de l'herbe et de la conduite des animaux au pâturage

Les effets du stade de l'herbe et du mode de pâturage sur la teneur du lait en terpènes ont été mesurés dans un essai conduit sur une prairie permanente diversifiée de montagne (Tornambé et al 2006). Une même parcelle, divisée en deux sous-parcelles homogènes a été exploitée en pâturage tournant rapide vs. lent (nouvelles surfaces allouées aux vaches respectivement tous les 2 jours ou 10 jours), au cours du $1^{\text {er }}$ cycle de végétation puis sur les repousses. Quarantesix composés terpéniques ont été identifiés dans les laits. Entre le début et la fin du 1 er cycle de végétation, la concentration du lait en terpènes a été multipliée par 8 et par 2 respectivement en rotation rapide et lente ; sur les repousses, la concentration en terpènes a été très faible (figure 5). Cette importante variabilité de réponse, observée sur une même parcelle, en fonction du cycle de végétation, du stade de l'herbe et du mode de pâturage complexifie l'utilisation des terpènes comme outils d'authentification de la provenance et/ou de la nature de l'alimentation.

Figure 5. Teneur du lait en monoterpènes selon la date et le mode de pâturage (pâturage tournant rapide (o) vs. pâturage tournant lent (•)). (Tornambé et al 2006).

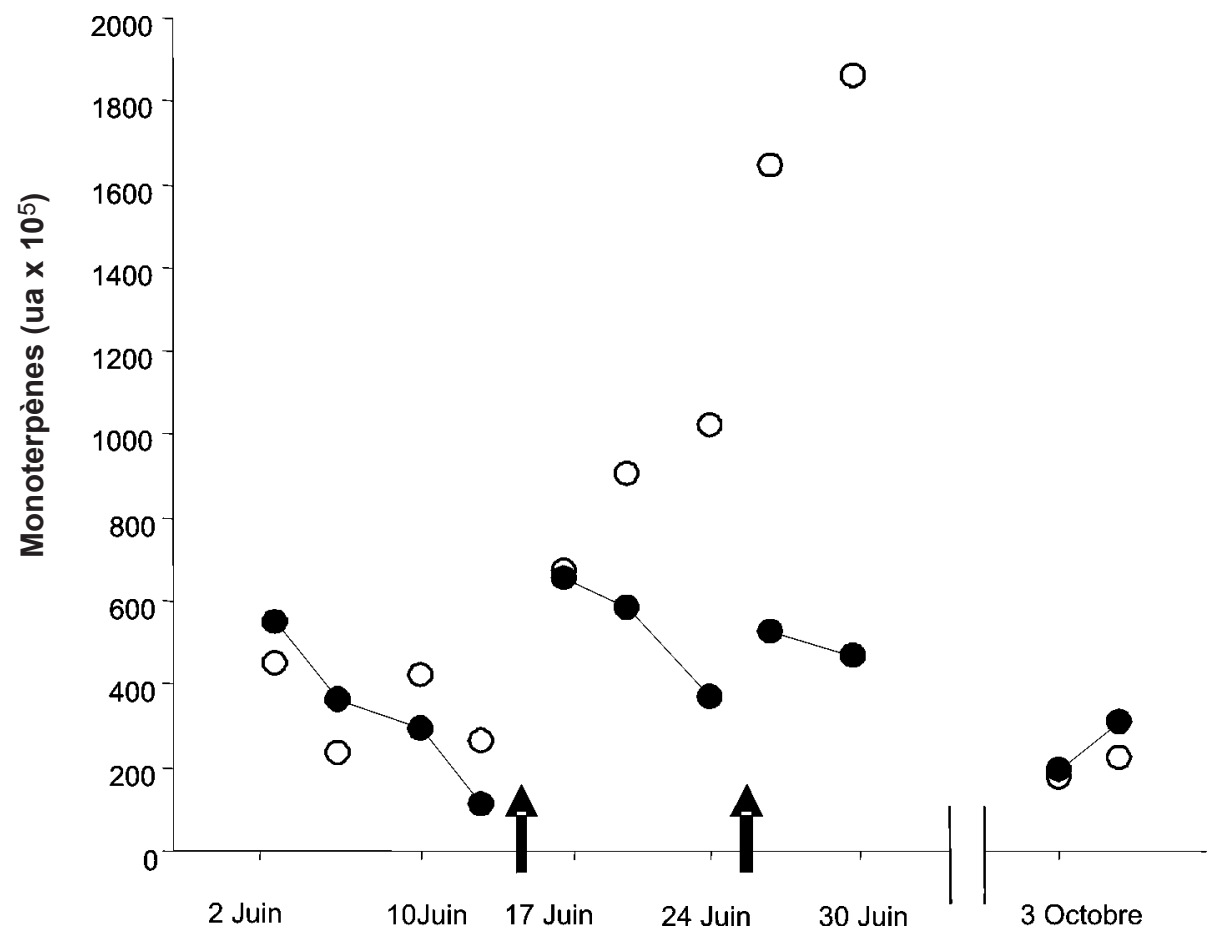

$\uparrow=$ changement de parcelle pour le lot pâturage tournant lent. b) Loi de réponse entre la quantité de traceurs ingérée par l'animal et leur concentration dans les tissus et produits

Il est important d'établir, lorsque c'est possible, la loi de réponse entre la quantité de traceur ingérée par l'animal et sa concentration dans les tissus et produits. Celle-ci a été étudiée pour les pigments caroténoïdes chez la vache laitière et l'agneau. Elle permet d'apporter des éléments de réponse assez génériques à des questions telles que l'effet de la teneur de l'herbe en ces pigments et l'effet du niveau d'ingestion d'herbe, qui peut être modulé par des facteurs de conduite au pâturage, tels que les quantités d'herbe offertes et la complémentation. Cette loi de réponse permet également de préciser les limites des pigments caroténoïdes comme traceurs de l'alimentation à l'herbe. En effet, même s'il s'agit toujours d'herbe, l'apport à l'auge d'herbe conservée par voie humide ou deshydratée n'a pas la même image positive auprès des consommateurs que le pâturage, et certains aliments tels que l'ensilage d'herbe peuvent être limités voire interdits dans certains cahiers des charges.

Chez la vache Holstein en milieu de lactation, la loi de réponse dans le plasma et le lait à un apport croissant d'un aliment expérimental riche en caroté- noïdes en substitution d'un foin de dactyle pauvre en ces micro-constituants a été étudiée par Calderón et al (2007). Le niveau d'ingestion de caroténoïdes variait de 1.6 à $7.4 \mathrm{~g} / \mathrm{j}$, soit de 150 à $1630 \mathrm{mg} / \mathrm{j}$ pour le $\beta$-carotène. Le $\beta$ carotène et l'index spectrocolorimétrique (IS) plasmatiques ont augmenté linéairement avec la quantité de caroténoïdes ingérés. Après stabilisation des teneurs plasmatiques (à partir de 6 semaines avec le régime le plus riche), une variation de $1 \mathrm{~g} / \mathrm{j}$ de l'ingestion de $\beta$-carotène s'est traduite en moyenne par une variation de $4 \mu \mathrm{g} / \mathrm{mL}$ de la teneur en $\beta$-carotène plasmatique. Il faut toutefois souligner que la teneur en caroténoïdes du régime le plus riche restait inférieure à celle observée pour l'herbe verte feuillue. Les teneurs en $\beta$ carotène et l'IS du lait, ainsi que les quantités sécrétées, ont, elles, augmenté de manière curvilinéaire avec la quantité de $\beta$-carotène ingéré, une saturation de la concentration dans le lait étant observée au delà d'une ingestion de $650 \mathrm{mg} ß$-carotène par jour (plateau à $4.8 \mu \mathrm{g} / \mathrm{g}$ de $\mathrm{MG}$ ). Ces résultats suggèrent l'existence de 2 facteurs de régulation de la sécrétion de $\beta$-carotène dans le lait en milieu de lactation : en dessous d'un niveau seuil de $\beta$-carotène plasmatique (de l'ordre de $5 \mu \mathrm{g} / \mathrm{mL}$ dans cet essai), la teneur en $\beta$-carotène du lait est limitée par les quantités de $\beta$ carotène ingérées. En revanche, au dessus de ce seuil, la teneur en $\beta$-carotène du lait semble limitée par les mécanismes impliqués dans le transfert de $\beta$ carotène du plasma vers le lait. Compte tenu de ces différences de réponse, le niveau de discrimination entre régimes plus ou moins riches en caroténoïdes sera probablement meilleur si l'on utilise les mesures de concentrations et d'IS dans le plasma que dans le lait.

Chez l'agneau, nous avons comparé 7 lots : 6 lots ont reçu des quantités journalières de luzerne deshydratée variant entre 0 et $1250 \mathrm{~g} / \mathrm{j}$ pendant $60 \mathrm{j}$ avant abattage et un lot a pâturé de l'herbe verte feuillue (Dian et al 2007b). La concentration en caroténoïdes plasmatiques et l'index spectrocolorimétrique du tissu adipeux à l'abattage ont augmenté linéairement avec l'apport journalier de luzerne, les équations obtenues permettant d'éclairer les questions relatives aux effets de la teneur de l'herbe en pigments caroténoïdes, de la disponibilité en herbe et de la complémentation. L'utilisation combinée de ces deux mesures a permis de distinguer sans erreur les agneaux au pâturage des agneaux recevant jusqu'à $500 \mathrm{~g}$ de luzerne par jour à l'auge, mais 
ces mesures seules ont été insuffisantes dans le cas d'un apport de luzerne supérieur. Comme dans l'exemple de la comparaison des six régimes alimentaires sur vaches laitières, c'est seulement la mise en œuvre simultanée de différentes techniques analytiques présentées plus haut qui a permis de discriminer sans erreur les agneaux élevés au pâturage de ceux qui ont reçu des quantités importantes de luzerne deshydratée (Prache et al non publié).

c) Risques de biais liés à des contaminations exogènes

Les huiles essentielles, riches en terpènes, sont parfois utilisées chez les animaux d'élevage en phytothérapie et comme facteurs d'appétence dans les aliments concentrés. Ces pratiques peuvent conduire à des apports élevés, chez des animaux alimentés à l'auge, de terpènes et composés phénoliques, potentiellement traceurs de l'alimentation au pâturage. De plus, certains composés volatils peuvent pénétrer dans l'organisme animal par voie cutanée ou respiratoire. Ainsi, des veaux exposés à une atmosphère enrichie en terpènes, mais qui n'en avaient pas ingéré, ont présenté des teneurs en terpènes importantes dans leurs tissus adipeux et lipides musculaires (Serrano et al 2007). Cependant, ce sont principalement les monoterpènes qui sont absorbés par voie respiratoire, les sesquiterpènes l'étant très peu. De plus, certains tissus adipeux comme le périrénal et l'intrapéritonéal semblent plus sélectifs des terpènes alimentaires que le sous cutané (Serrano et al 2007).

\section{2 / Latence et persistance lors d'un changement d'alimenta- tion}

\section{a) Produits laitiers}

La cinétique de transfert des terpènes des fourrages à la matière grasse du lait a été étudiée par Viallon et al (2000). Lorsque l'on distribue un fourrage riche en terpènes à des vaches laitières, le passage de ces composés dans le lait est rapide : il est observé dès la première traite après le premier repas, la concentration maximale étant atteinte 3 jours après le début de la distribution. Inversement, lorsque l'on cesse la distribution de ce fourrage, les teneurs en terpènes reviennent rapidement (3 jours) à leur valeur initiale. Le dosage des terpènes de la matière grasse du lait fournit donc une information à court terme sur la consommation par l'animal de fourrages riches en ces composés.

La latence d'apparition et la persistance des caroténoïdes dans le sang et le lait ont été récemment étudiées chez la vache en milieu de lactation. Lors du passage d'une ration riche en caroténoïdes à une ration pauvre en ces micro-constituants, les teneurs en ß-carotène, ainsi que l'index spectrocolorimétrique (IS) du lait et du plasma ont commencé à diminuer dès le changement de régime puis elles se sont stabilisées après environ 2 semaines. Ainsi, l'utilisation combinée de l'IS du plasma et de l'IS du lait a permis de discriminer sans erreur le régime des animaux après 15 jours de mise en régime (figure 6, Nozière et al 2006a). Réciproquement, lors du passage d'une ration pauvre en ces micro-constituants à une ration comprenant une proportion variable $(0,33$, 66 ou $100 \%)$ d'un aliment expérimental riche en caroténoïdes, les teneurs en $\beta$-carotène, ainsi que l'IS du plasma, ont augmenté très rapidement. L'augmentation a été d'autant plus rapide et la stabilisation atteinte d'autant plus tardivement que la proportion d'aliment expérimental dans le régime était plus élevée (de 4 à plus de 6 semaines pour le $\beta$-carotène et de 2 à 6 semaines pour l'IS). Des réponses différentes ont été observées dans le lait: la vitesse d'apparition et la concentration maximale du $\beta$-carotène dans le lait ont été indépendantes de la proportion d'aliment expérimental, un plateau étant observé au-delà d'une ingestion de $650 \mathrm{mg}$ de $\beta$-carotène par jour (Calderón et al 2007). Ainsi, l'utilisation de l'IS du plasma et de l'IS du lait n'a permis de discriminer totalement les régimes extrêmes ( $0 v s$ 100\% d'aliment expérimental) qu'après 6 semaines de mise en régime.

\section{b) Produits carnés}

Nous avons étudié comment la finition en bergerie d'agneaux préalablement élevés à l'herbe affecte la concentration des produits et tissus en traceurs d'intérêt de l'alimentation à l'herbe, à partir de la comparaison de 3 lots d'agneaux qui, soit pâturaient de l'herbe verte feuillue $(\mathrm{H})$, soit étaient alimentés en bergerie avec du concentré et du foin (B), soient étaient finis en bergerie avec du concentré et du foin pendant une durée variable après une phase de pâturage (HB). La teneur en caroténoïdes plasmatiques diminue de manière exponentielle avec la durée de finition, avec une persistance moyenne de 8 jours (figure 7, Prache et al 2003a). La variation de concentration de ces pigments dans le tissu adipeux lors de la finition est liée à la dilution des pigments préalablement stockés, donc plus au gain de poids déposé en finition qu'à la durée de finition stricto sensu (Prache et al 2003b). Le modèle développé à partir du gain de poids en finition et de la teneur en caroténoïdes plasmatiques à la fin de la période de pâturage permet de prédire que l'index spectrocolorimétrique (IS) du tissu adipeux des agneaux HB atteint celui des agneaux B après $11 \mathrm{~kg}$, soit 35 jours si la croissance est de $300 \mathrm{~g} / \mathrm{j}$ en finition. La persistance des pigments caroténoïdes est donc plus longue dans le tissu adipeux périrénal que dans le plasma. Il est intéressant de souligner que, compte tenu des différences de persistance

Figure 6. Distribution des index spectrocolorimétriques du plasma et du lait chez la vache alimentée avec du foin (o) ou de l'ensilage d'herbe (•) après $1,8,15$ ou 43 jours sur le régime (Nozière et al 2006a).

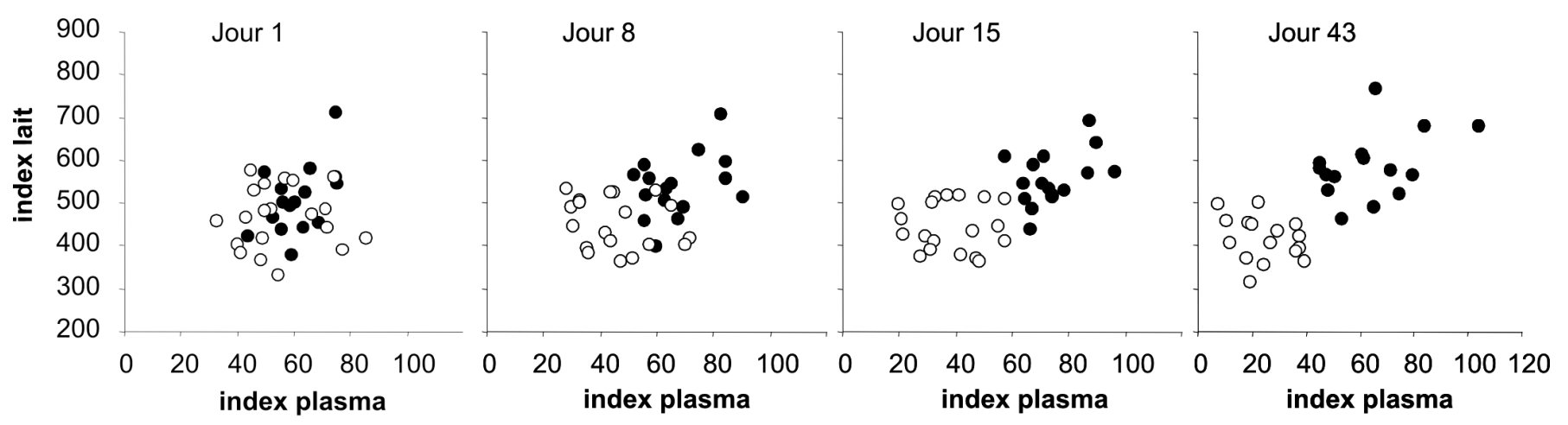


Figure 7. Evolution de la teneur plasmatique en caroténoïdes avec la durée de finition en bergerie chez des agneaux élevés à l'herbe puis finis en bergerie (Prache et al 2003a).

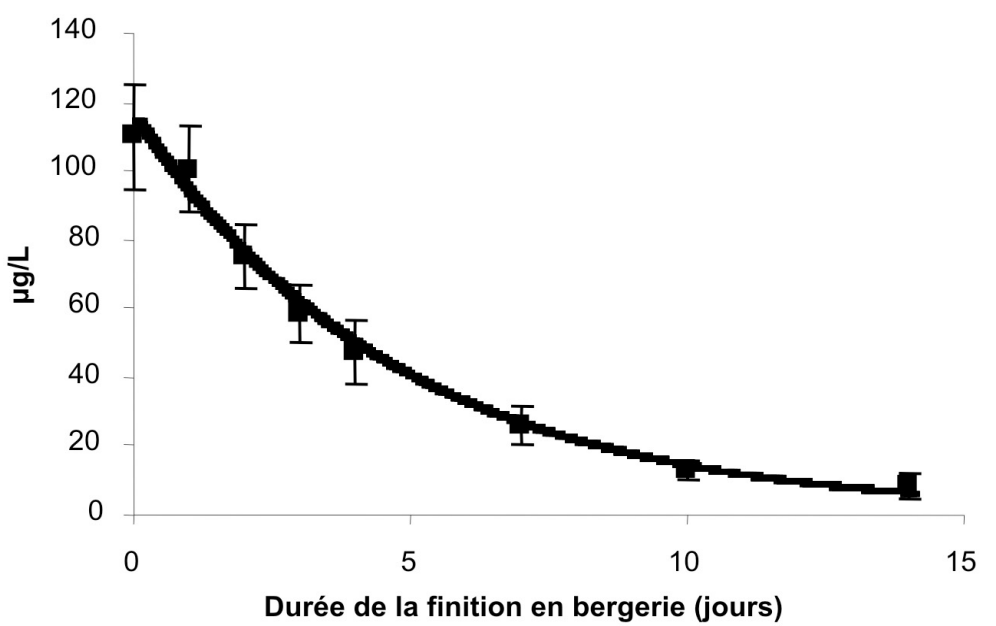

entre les deux tissus, l'utilisation combinée des mesures sur le plasma et le tissu adipeux donne des informations complémentaires et permet d'affiner le résultat (Prache et al 2003b). Ainsi, lorsqu'on observe un IS du gras élevé associée à une teneur plasmatique en caroténoïdes faible, on peut en conclure qu'il s'agit d'un agneau élevé à l'herbe et fini en bergerie (tableau 1). Dans cette étude, la persistance des terpènes dans le tissu adipeux sous cutané a été faible ; avec une analyse discriminante à partir de 4 terpènes, nous avons pu discriminer les agneaux $\mathrm{H}$ des agneaux B et HB, mais pas les agneaux HB des agneaux B (Priolo et al 2004). Parmi les composés volatils, la 2,3- octanedione, qui diminue de manière exponentielle avec la durée de finition, présente l'intérêt d'être peu sensible à la variabilité inter-individuelle (Priolo et al 2004).

L'effet de la finition à l'auge avec de l'ensilage de maïs sur la composition isotopique de la viande et du tissu adipeux de boeufs préalablement au pâturage a été étudié par Gebbing et al (2004). Ces auteurs ont comparé 2 lots de bœufs alimentés pendant 230 jours soit avec de l'ensilage de maïs (plante en $\mathrm{C}_{4}$ ) soit avec de l'ensilage d'herbe (plantes en $\mathrm{C}_{3}$ ) après une phase de pâturage (plantes en $\mathrm{C}_{3}$ ). Les deux régimes de finition ont conduit à des pro-

Tableau 1. Distribution d'agneaux de race lle de France selon l'utilisation combinée de la teneur en carotenoïdes plasmatiques et de l'index spectrocolorimétrique (IS) du gras périrénal à l'abattage. D'après Prache et al (2003b).

\begin{tabular}{|c|c|c|c|}
\hline & $\begin{array}{c}\text { Nombre } \\
\text { d'agneaux }\end{array}$ & $\begin{array}{l}\text { Concentration } \\
\text { plasmatique en } \\
\text { caroténoïdes à } \\
\text { l'abattage }(\mu \mathrm{g} / \mathrm{L})\end{array}$ & $\begin{array}{c}\text { Index } \\
\text { spectrocolorimétrique } \\
\text { (IS) du gras périrénal } \\
\text { à l'abattage (unités) }\end{array}$ \\
\hline Agneaux d'herbe ${ }^{(1)}$ & 8 & $>36,6$ & $>152$ \\
\hline Agneaux de bergerie ${ }^{(2)}$ & 8 & $<20,6$ & $<152$ \\
\hline $\begin{array}{l}\text { Agneaux d'herbe finis } \\
\text { en bergerie }\end{array}$ & 6 & $<20,6$ & $>152$ \\
\hline $\begin{array}{l}\text { Agneaux d'herbe finis } \\
\text { en bergerie }\end{array}$ & 10 & $<20,6$ & $<152$ \\
\hline
\end{tabular}

(1) Les agneaux d'herbe présentent une concentration sanguine élevée et un IS élevé du gras périrénal élevé.

(2) Les agneaux de bergerie présentent une concentration sanguine faible et un IS faible du gras périrénal.

(3) Lorsque l'on observe un IS élevé du gras périrénal associée à une concentration sanguine faible ( 6 agneaux dans la présente étude), on peut en conclure qu'il s'agit d'un agneau élevé à l'herbe et fini en bergerie. Ceci est dû aux différences de persistance des pigments caroténoïdes dans le sang et le gras.

(4) Un certain nombre d'agneaux d'herbe finis en bergerie présentent des valeurs qui se situent dans la gamme de celles observées pour les agneaux de bergerie (10 agneaux dans la présente étude) : il s'agit d'agneaux qui absorbent et fixent peu ces pigments ou d'agneaux qui ont subi une finition de longue durée en bergerie.

portions différentes d'isotopes stables du carbone dans le muscle long dorsal et le gras périrénal à l'abattage. La durée d'engraissement à l'ensilage de maïs a cependant été insuffisante pour provoquer un turn-over complet du carbone du tissu musculaire, dont l'enrichissement en ${ }^{13} \mathrm{C}$ était lié à l'importance de la prise de poids en finition. Cette dernière liaison n'était pas observée dans le gras périrénal, probablement en lien avec un dépôt plus tardif de ce tissu.

Une des conclusions importantes à tirer de ces deux exemples sur la viande (l'un sur la viande ovine, l'autre sur la viande bovine) est que le profil de persistance peut varier selon le traceur et le tissu considéré, et qu'il peut donc être intéressant de tirer avantage de ces différences pour affiner la prédiction et le contrôle de la durée d'alimentation sur un régime donné.

\section{4 / Exemples de validation à grande échelle et d'applica- tion sur le terrain avec les filières}

La majorité des études rapportées cidessus, qui ont été réalisées en situations expérimentales, ont montré une grande variabilité de la réponse animale. Ceci nécessite donc la mise en place d'essais de validation à grande échelle. Certains de ces essais sont en cours, pour les produits laitiers et carnés, en installations expérimentales et domaines INRA, mais aussi en exploitations privées en collaboration avec certaines filières intéressées par ces outils.

\section{1 / Viande ovine}

Nous avons démarré depuis plusieurs années une validation de certaines des méthodes exposées ici, sur des effectifs importants et plusieurs races ovines. Un premier travail a été effectué sur environ 300 agneaux de race Limousine élevés soit à l'herbe, soit en bergerie avec du concentré et du foin (Dian et al 2007a). La proportion d'agneaux correctement classés a été de $91 \%, 89 \%$ et $94 \%$ en utilisant respectivement la concentration en caroténoides plasmatiques, l'index spectrocolorimétrique sur le gras périrénal et la méthode spectrale VIS sur le gras périrénal. La fiabilité a donc été inférieure à celle obtenue précédemment sur des effectifs limités (100\% pour les 3 méthodes). Ceci est probablement à relier à une plus grande 
variabilité dans le niveau d'ingestion et d'absorption des caroténoïdes. Le premier dépend en effet en partie de la teneur de l'herbe en ces pigments, qui a probablement varié de manière importante dans ce travail de validation, puisque les agneaux élevés à l'herbe ont été abattus entre les mois d'août et novembre, alors qu'ils avaient été abattus en juillet et août dans les études précédentes. Le niveau d'ingestion de caroténoïdes a probablement aussi varié avec le niveau d'ingestion d'herbe, dont on sait qu'il peut être très variable entre animaux (Prache et Thériez 1988). Ces résultats illustrent la nécessité d'une validation des méthodes et des résultats sur de grands effectifs, en particulier dans le cas de l'alimentation à l'herbe, aliment dont les caractéristiques et l'ingestibilité peuvent être extrêmement variables. Cette validation est en cours pour d'autres races ovines, la capacité à stocker les pigments caroténoïdes ayant une forte composante génétique (Nozière et al 2006b). Au-delà des caroténoïdes plasmatiques et de l'index spectrocolorimétrique, cette validation associe également les méthodes spectrales VIS et VIS-IR. Elle est en cours dans des installations expérimentales INRA et également chez des éleveurs produisant des agneaux d'herbe et des agneaux de bergerie, avec notamment une collaboration avec la filière d'agneaux de PréSalé de la Baie du Mont Saint-Michel, qui prend des engagements spécifiques sur le processus de production des agneaux (voir Prache et al 2005).

\section{2 / Produits laitiers}

La pertinence des biomarqueurs mis au point sur des régimes expérimentaux contrastés pour vaches laitières a été testée sur des laits de grand mélange collectés par les industriels du département de la Haute-Loire. Ces laits étaient issus de 50 collectes dans 11 à 36 exploitations situées dans des zones de production variant par l'altitude (450 à $1100 \mathrm{~m}$ ) et le système fourrager («maïs dominant» à «tout herbe»). L'enrichissement de l'eau du lait en ${ }^{18} \mathrm{O}$ a été plus important en plaine $(<500 \mathrm{~m})$ qu'en montagne $(>700 \mathrm{~m})$, mais la mesure du rapport $\delta^{18} \mathrm{O}$ n'a pas permis de discriminer systématiquement la provenance du lait, en raison d'une importante variabilité saisonnière (Engel et al 2007). Les terpènes ont confirmé leur intérêt pour authentifier la provenance (plaine/montagne), mais les composés du lait présentant le meilleur potentiel de discrimination à la fois de la provenance et du système fourrager ont été les acides gras (Engel et al 2007). La sélection de 2 rapports d'acides gras (iso-C17:0/C18:3n-3 et iso-C15:0/iso-C14:0) a permis de différencier sans erreur les laits de montagne des laits de plaine. La sélection de deux autres rapports d'acides gras (trans 11cis15-C18:2/trans11-C18:1 et cis9-C16:1/isoC16:0) a permis de discriminer sans erreur les laits en fonction de la proportion de maiis dans les fourrages $(<25 \% v s>30 \%)$. Les caroténoïdes et l'index spectrocolorimétrique n'ont pas confirmé leur intérêt dans cette étude, mais les méthodes spectrales (VIS-IR, VIS et fluorescence frontale) ont permis de classer correctement respectivement $91 \%, 84 \%$ et 69 $\%$ des échantillons selon leur provenance (plaine/montagne) (Karoui et al 2005, Martin et al 2006).

\section{Conclusions}

Ces recherches finalisées sur l'authentification de l'alimentation des ruminants s'inscrivent dans un contexte général de demandes d'informations et de garanties sur les conditions d'élevage des animaux. Dans ce contexte, il $\mathrm{y}$ a un besoin de méthodes analytiques permettant de garantir de manière objective le respect des engagements imposés dans les cahiers des charges, voire permettant de les instruire. Les premiers résultats indiquent qu'il est possible de discriminer certains types d'alimentation contrastés en utilisant des méthodes analytiques quantifiant des composés spécifiques ou des méthodes plus globales. La discrimination peut cependant être imparfaite quand les méthodes sont utilisées isolément, et il peut y avoir des complémentarités/synergies entre les différents outils et les différents tissus ou produits. Les premiers résultats obtenus en situations d'alternance de régimes, plus difficiles à caractériser, renforcent l'idée de combiner différents composés traceurs et différents tissus, du fait des différences de profils de latence et/ou de persistance observés. Le coût et la facilité de mise en oeuvre varient entre méthodes. Les méthodes spectrales, simples d'utilisation et peu coûteuses, peuvent être utilisées facilement sur un grand nombre d'échantillons. D'autres méthodes plus coûteuses et délicates à mettre en œuvre, telles que l'analyse des composés volatils ou des polyphénols, ne peuvent pas être actuellement envisagées sur un grand nombre d'échantillons, mais l'éventualité de leur utilisation peut dissuader des fraudes. Enfin, ces méthodes pourraient être couplées par paliers, les plus simples sur un plus grand nombre d'animaux, les plus coûteuses en dernier ressort.

La majorité des études montrant une grande variabilité de la réponse animale, ceci conduit à s'intéresser maintenant aux sources possibles de variation et à la quantification de leurs effets. Le stade phénologique des plantes et la composition botanique des prairies peuvent ainsi affecter les teneurs en traceurs d'intérêt. Une étude de la variabilité des profils de polyphénols et de caroténoïdes dans les prairies vient ainsi de démarrer dans différentes régions françaises. De même, la disponibilité en herbe et la complémentation au pâturage, par exemple, peuvent moduler l'ingestion d'herbe et donc l'ingestion des traceurs correspondants. Plus généralement, il serait important d'établir, lorsque c'est possible, les lois de réponse entre la quantité de traceurs ingérée par l'animal et leur concentration dans les tissus et produits. Les facteurs de variation spécifiquement animaux, tels que la race et le niveau de production, peuvent également moduler la réponse animale et doivent être prochainement étudiés. Cette variabilité rend également indispensable une validation à grande échelle. Celle-ci est en cours pour les produits laitiers et carnés, avec la constitution de bases de données issues des installations expérimentales et domaines INRA, mais aussi en exploitations privées en collaboration avec certaines filières intéressées par ces outils.

\section{Remerciements}

Nous remercions le personnel de l'Installation Expérimentale et de l'Abattoir de l'UR Herbivores, le personnel technique de l'UR Herbivores et de 1'UR Qualité des Produits Animaux, ainsi que le personnel des Unités Expérimentales INRA de Marcenat et des Mont Dore impliqué dans ces travaux. Nous remercions également les personnes des différentes filières qui ont participé à la réflexion et à la réalisation de certaines études. Certains programmes ont reçu un soutien financier de l'Institut National des Appellations d'Origine (INAO), de l'ANR dans le cadre de son programme thématique Agriculture et Développement Durable (projet PRODDIG Promotion du Développement Durable par les Indications Géographiques), de la Chambre d'Agriculture et du Conseil Général de la Haute Loire, du département PHASE et de l'UR Herbivores de I'INRA. 


\section{Références}

Aurousseau B., Bauchart D., Calichon E., Micol D., Priolo A., 2004. Effect of grass or concentrate feeding systems and rate of growth on triglyceride and phospholipid and their fatty acids in the M. longissimus thoracis of lambs. Meat Sci., 66, 531-541.

Berdagué J.L., Engel E., Levieux D., Renou J.P., 2005. In: Du gène à l'assiette, Revue d'Auvergne, Alliance Universitaire d'Auvergne (Ed), Clermont-Ferrand, France, 245-259.

Besle J.M., Lamaison J.L., Dujol B., Pradel P., Fraisse D., Viala D., Martin B., 2005. Flavonoids and other phenolics in milk as a putative tool for traceability of dairy production systems. In: Indicators of milk and beef quality, Hocquette J.F., Gigli S. (Eds), Wageningen Academic Publishers, Wageningen, The Netherlands, EAAP Publication, 112, 345-350.

Bosset J.O., Bütikofer U., Gauch R., Sieber R., 1994. Caractérisation de fromages d'alpages subalpins suisses : mise en évidence par GC-MS de terpènes et d'hydrocarbures aliphatiques lors de l'analyse par «Purge and Trap» des arômes volatils de ces fromages. Schweiz. Milchw. Forschung, 23, 37-41.

Bugaud C., Buchin S., Coulon J.B., Hauwuy A., Dupont D., 2001. Influence of the nature of alpine pastures on plasmin activity, fatty acid and volatile compound composition of milk. Le Lait, 81, 401-414.

Calderón F, Chauveau-Duriot B., Pradel P., Martin B, Graulet B., Doreau M., Nozière P., 2007. Variations in carotenoids, Vitamins A and $\mathrm{E}$, and color in cow's plasma and milk following a shift from hay diet to diets containing increasing levels of carotenoids and vitamin E. J. Dairy Sci., sous presse.

Carpino S., Mallia S., Terra S., Melilli C., Licitra G., Acree T.E. Barbano D.M., Van Soest P.J., 2004. Composition and aroma compounds of Ragusano cheese: native pasture and total mixed rations. J. Dairy Sci., 87, 816-830.

Cassar-Malek I., Bernard C., Jurie C., Barnola I., Gentès G., Dozias D., Micol D., Hocquette J.F., 2005. Pasture-based beef production systems may influence muscle characteristics and gene expression. In: Indicators of milk and beef quality, Hocquette J.F., Gigli S. (Eds), Wageningen Academic Publishers, Wageningen, The Netherlands, EAAP Publication, 112, 385-390.

Chilliard Y., Glasser F., Ferlay A., Bernard L., Rouel J., Doreau M., 2007. Diet, rumen biohydrogenation, cow and goat milk fat nutritional quality: a review. Eur. J. Lipid Sci. Technol., 109, 828-855.

Cornu A., Carnat A.P., Martin B., Coulon J.B., Lamaison J.L., Berdagué J.L., 2001a. Solid phase microextraction of volatile components from natural grassland plants. J. Agric. Fd Chem., 49, 203-209.

Cornu A., Kondjoyan N., Begnaud F., Micol D., Renou J.P., Berdagué J.L., 2001b. Les terpènes des viandes, traceurs de l'alimentation et de l'origine géographique des animaux. Renc. Rech. Rumin., 8, 61.

Cozzolino D., De Mattos D., Vaz Martins D., 2002. Visible/near infrared reflectance spectroscopy for predicting composition and tracing system of production of beef muscle. Anim. Sci., 74, 477-484.

Deport C., Ratel J., Berdagué J.L., Engel E., 2006. Comprehensive combinatory standard cor- rection: a calibration method for handling instrumental drifts of gas chromatography-mass spectrometry systems. J. Chromatogr. A, 1116, 248258.

Dian P.H.M., Andueza D., Barbosa C.P., Amoureux S., Jestin M., Carvalho P.C.F., Prado I.N., Prache S., 2007a. Methodological developments in the use of visible reflectance spectroscopy for discriminating pasture-fed from concentrate-fed lamb carcasses. Animal, 1, 1198-1208.

Dian P.H.M., Chauveau-Duriot B., Prado I.N., Prache S., 2007b. A dose-response study relating the concentration of carotenoid pigments in blood and fat reflectance spectrum characteristics to the carotenoid intake level in sheep. J. Anim. Sci., 85, 3054-3061.

Dumont J.P., Adda J., 1978. Occurrence of sesquiterpenes in mountain cheese volatiles. J. Agric. Fd Chem., 26, 364-367.

Dumont J.P., Adda J., Rousseau P., 1981. Exemple de variation de l'arôme à l'intérieur d'un même type de fromage : le Comté. Lebensm. Wiss. u. Technol., 14, 198-202.

Engel E., Ratel J., 2006. In: Proc of the IUFOST XIIIth World Congress of Food Sci. and Techn. "FOOD IS LIFE", sous presse.

Engel E., Ferlay A., Cornu A., Chilliard Y., Agabriel C., Bielicki G., Martin B., 2007. Relevance of isotopic and molecular biomarkers for the authentication of milk according to production zone and type of feeding of the cow. J. Agric. Fd Chem., sous presse.

Ferlay A., Martin B., Pradel P., Coulon J.B., Chilliard Y., 2006. Influence of grass-based diets on milk fatty acid composition and milk lipolytic system in Tarentaise and Montbéliarde cow breeds. J. Dairy Sci., 89, 4026-4041.

Fernandez C., Astier C., Rock E., Coulon J.B., Berdagué J.L., 2003. Characterization of milk by analysis of its terpene fraction. Int. J. Fd Sci. Technol. 38, 445-451.

Fraisse D., Carnat A., Viala D., Pradel P., Besle J.M., Coulon J.B., Felgines C., Lamaison J.L, 2007. Polyphenolic composition of a permanent pasture. Variations related to the period of harvesting. J. Sci. Fd Agric., 87, 2427-2435.

Gebbing T., Schellberg J., Kühbauch W., 2004. Switching from grass to maize changes the $\mathrm{C}$ isotope signature of meat and fat during fattening of steers. Proc. 20 ${ }^{\text {th }}$ Gen. Meet. Eur. Grassland Fed., Lüscher A., Jeangros B., Kessler W., Huguenin O., Lobsiger M., Millar N., Suter D. (eds), Luzern, Switzerland, 1130-1132.

Hocquette J.F., Cassar-Malek I., Listrat A., Picard B., 2005. Current genomics in cattle and application to beef quality. In: Indicators of milk and beef quality, Hocquette J.F., Gigli S. (Eds), Wageningen Academic Publishers, Wageningen, The Netherlands, EAAP Publication 112, 65-79.

Karoui R., Martin B., Dufour E., 2005. Potentiality of front-face fluorescence spectroscopy to determine the geographic origin of milks from the Haute-Loire department (France). Le Lait, 85, 223-236.

Kornexl B.E., Werner T., Rossmann A., Schmidt H.L., 1997. Measurements of stable isotope abundances in milk and milk ingredients - a possible tool for origin assignment and quality control. Z. Lebensm. Unters. Forsch. A, 205, 1924.
Mariaca R.G., Berger T.F.H., Gauch R., Imhof M.I., Jeangros B., Bosset J.O., 1997. Occurrence of volatile mono- and sesquiterpenoids in highland and lowland plant species as possible precursors for flavor compounds in milk and dairy products. J. Agric. Fd Chem., 45, 4423-4434.

Martin B., Cornu A., Kondjoyan N., Ferlay A., Verdier-Metz I., Pradel P., Rock E., Chilliard Y., Coulon J.B., Berdagué J.L., 2005. Milk indicators for recognizing the types of forages eaten by dairy cows. In: Indicators of milk and beef quality, Hocquette J.F., Gigli S. (Eds), Wageningen Academic Publishers, Wageningen, The Netherlands, EAAP Publication 112, 127-136.

Martin B., Jestin M., Constant I., Agabriel C., Andueza D., 2006. Authentification de la zone de production de laits de grands mélanges (plaine-montagne) à partir de méthodes spectrales dans le visible et le proche infra-rouge. Renc. Rech. Rumin., 13, 194.

Nozière P., Andueza D., Meunier B., Micol D. 2005. Mise au point d'un dispositif de contrôle sur l'animal de la quantité de concentré ingéré par des bovins en finition. Renc. Rech. Rumin. $12,390$.

Nozière P., Grolier P., Durand D., Ferlay A., Pradel P., Martin B., 2006a. Variation of carotenoids, fat-soluble micronutrients and color in cow's plasma and milk following changes in forage and feeding level. J. Dairy Sci., 89, 26342648 .

Nozière P., Graulet B., Lucas A., Martin B., Grolier P., Doreau M., 2006b. Carotenoids in ruminants: from forage to dairy products. Anim. Feed Sci. Techn., 131, 418-450.

Nozière P., Calderón F., Martin B., Prache S., Pradel P., Papon Y., Jestin M., Andueza D., 2006c. Comparaison de deux méthodes spectrales pour tracer l'alimentation de vaches laitières à partir du lait. Renc. Rech. Rumin., 13, 192.

Piasentier E., Valusso R., Camin F., Versini G., 2003. Stable isotope ratio analysis for authentication of lamb meat. Meat Sci., 64, 239-247.

Prache S., Thériez M., 1988. Production d'agneaux à l'herbe. INRA Prod. Anim., 1, 25-33.

Prache S., Thériez M., 1999. Traceability of lamb production systems: carotenoids in plasma and adipose tissue. Anim. Sci., 69, 29-36.

Prache S., Priolo A., 2003. Procédé de traçabilité d'une alimentation avec de l'herbe fraîche chez un animal. Accord de délivrance du 24 oct 2003 du brevet d'invention priorité $\mathrm{N}^{\circ} 010560$, déposé en France au nom de l'INRA à l'Institut de la Propriété Industrielle, Paris, France.

Prache S., Priolo A., Tournadre H., Jailler R., Dubroeucq H. Micol D., Martin B, 2002. Traceability of grass feeding by quantifying the signature of carotenoid pigments in herbiovores meat, milk and cheese. In: Proc. $1^{\text {th }}$ Gen. Meet. Eur. Grassland Fed., Durand J.L., Emile J.C., Huyghe C., Lemaire G. (Eds.), La Rochelle, France, 592-593.

Prache S., Priolo A., Grolier P., 2003a. Persistence of carotenoid pigments in the blood of concentrate-finished grazing sheep: its significance for the traceability of grass feeding. J. Anim. Sci., 81, 360-367.

Prache S., Priolo A., Grolier P., 2003b. Effect of concentrate finishing on the carotenoid content of perirenal fat in grazing sheep: its signifi- 
cance for discriminating grass-fed, concentratefed and concentrate-finished grazing lambs. Anim. Sci., 77, 225-233.

Prache S., Cornu A., Berdagué J.L., Priolo A., 2005. Traceability of animal feeding diet in the meat and milk of small ruminants: a review. Small Rumin. Res., 59, 157-168.

Priolo A., Prache S., Micol D, Agabriel J., 2002. Reflectance spectrum of adipose tissue to trace grass feeding in sheep: influence of measurement site and shrinkage time after slaughter. J. Anim. Sci., 80, 886-891.

Priolo A., Cornu A., Prache S., Krogmann M, Kondjoyan N., Micol D., Berdagué J.L., 2004. Fat volatile tracers of grass feeding in sheep. Meat Sci., 66, 475-481.

Renou J.P., Deponge C., Gachon P., Bonnefoy J.C., Coulon J.B., Garel J.P. Vérité R., Ritz P., 2004a. Characterization of animal products according to geographic origin and feeding diet using nuclear magnetic resonance and isotope ratio mass spectrometry: cow milk. Fd Chem., 85 (1), 63-66.

Renou J.P., Bielicki G., Deponge C., Gachon P., Micol D., Ritz P., 2004b. Characterization of animal products according to geographic origin and feeding diet using nuclear magnetic resonance and isotope ratio mass spectrometry. Part II: Beef meat. Fd Chem., 86 (2), 251-256.
Roche B., Dedieu B., Ingrand S., 2000. Analyse comparative des cahiers des charges Label Rouge gros bovins de boucherie. Renc. Rech. Rumin., 7, 259-262.

Rossmann A., Haberhauer G., Hölzl S., Horn P., Pichlmayer F., Voerkelius S., 2000. The potential of multielement stable isotope analysis for regional origin assignment of butter. Eur. Fd Res. Technol., 211, 32-40.

Sakakibara H., Viala D., Ollier A., Combeau A., Besle J.M., 2004. Isoflavones in several clover species and in milk from goats fed clovers. Biofactors, 22, 237-239.

Serrano E., Cornu A., Andueza D., Chauveau B., Prache S., Pradel P., Micol D., 2006a. Traçabilité de l'alimentation à base de fourrages par l'empreinte des caroténoïdes, des terpènes et de la SPIR chez les jeunes bovins. In: 11 èmes JSMTV, 225-226.

Serrano E., Prache S., Chauveau-Duriot B. Agabriel J., Micol D., 2006b. Traceability of grass-feeding in young beef using carotenoid pigments in plasma and adipose tissue. Anim. Sci., 82, 909-918.

Serrano E., Cornu A., Kondjoyan N., Figueredo G., Agabriel J., Micol D., 2007. Terpene accumulation in muscle and fatty tissues of veal supplemented with essential oils, J. Anim. Feed Sci., 16, 168-179.
Schmidt O., Quilter J.M., Bahar B., Moloney A.P., Scrimgeour C.M., Begley I.S., Monahan F.J., 2005. Inferring the origin and dietary history of beef from $\mathrm{C}, \mathrm{N}$ and $\mathrm{S}$ stable isotope ration analysis. Fd Chem., 91, 545-549.

Tornambé G., Cornu A., Pradel P., Kondjoyan N., Carnat A.P., Petit M., Martin B., 2006. Changes in terpene content in milk from pasturefed cows. J. Dairy Sci., 89, 2309-2319.

Vasta V., Priolo A., 2006. Ruminant fat volatiles as affected by diet. A review. Meat Sci., $73,218-228$.

Viallon C., Verdier-Metz I., Denoyer C., Pradel P., Coulon J.B., Berdagué J.L., 1999. Desorbed terpenes and sesquiterpenes from forages and cheeses. J. Dairy Res., 66, 319-326.

Viallon C., Martin B., Verdier-Metz I., Pradel P., Garel J.P., Coulon J.B., Berdagué J.L., 2000 Transfer of monoterpenes and sesquiterpenes from forages into milk fat. Le Lait, 80, 635-641.

Vlaeminck B., Fievez V., Cabrita A.R.J., Fonseca A.J.M., Dewhurst R.J., 2006. Factors affecting odd and branched-chain fatty acids in milk: a review. Anim. Feed Sci. Techn., 131, 389-417.

Yang A., Larsen T.W., Tume R.K., 1992. Carotenoid and retinal concentrations in serum, adipose tissue and liver and carotenoids transport in sheep, goats and cattle. Aust. J. Agric. Res., 43, 1809-1817.

\section{Résumé}

Les consommateurs sont demandeurs d'informations et de garanties sur les conditions d'élevage des animaux et en particulier sur leur alimentation. Ces préoccupations conduisent les filières animales à prendre des engagements sur les conditions d'élevage et d'alimentation des animaux, engagements spécifiés dans des cahiers des charges. Il apparaît ainsi un besoin d'outils analytiques permettant de garantir le respect de ces engagements et/ou d'aider à les instruire. La nature de l'alimentation influence fortement la composition des tissus et produits animaux. Ceci est dû à des composés spécifiques qui sont soit directement transférés de l'aliment au produit, soit transformés ou produits par les microorganismes du rumen ou le métabolisme animal sous l'effet de l'alimentation. Certains de ces composés peuvent donc, en retour, être utilisés pour tracer l'alimentation. De plus, les différences de composition des tissus et produits provoquent des modifications de leurs propriétés optiques, qui peuvent également être mises à profit. Cet article présente les différentes approches analytiques développées actuellement, les principaux résultats obtenus lors de la comparaison d'alimentations contrastées, puis lors de l'alternance de régimes alimentaires avec les questions de latence et de persistance des biomarqueurs d'intérêt, et enfin quelques exemples d'application sur le terrain avec certaines filières animales intéressées par ces outils.

\section{Abstract}

\section{Diet authentication in ruminants from the composition of their products and tissues}

There is currently an increased consumer demand for information on herbivore production factors, particularly animal diet. To meet these demands, farmers and commercial entities develop specifications via quality labels. There is therefore a need for analytical tools that may guarantee that the specification commitments have been fully met or to help constructing them. The nature of the diet strongly influences the composition of the animal tissues and products, which is due to specific compounds that are directly transferred from the feed to the end product or that are transformed or produced by ruminal microorganisms or the animal's metabolism under the effect of specific diets. Some of these compounds can therefore be used as diet markers. Moreover, differences in the meat and milk composition induce differences in their optical properties, therefore in their spectral features, which can also be used for diet authentication. This paper reviews the different approaches that have been investigated, some leading results concerning the comparison of contrasting feeding situations, together with the persistence and latency of appearance of some diet markers in the event of animal diet changes, and lastly some examples of implementation in the field with farmers that are interested in such methods.

PRACHE S., MARTIN B., NOZIERE P., ENGEL E., BESLE J.-M., FERLAY A., MICOL D., CORNU A., CASSARMALEK I., ANDUEZA D., 2007. Authentification de l'alimentation des ruminants à partir de la composition de leurs produits et tissus. INRA Prod. Anim., 20, 295-308. 
